\title{
Low incidence of autoimmune type I diabetes in BB rats fed a hydrolysed casein-based diet associated with early inhibition of non-macrophage-dependent hyperexpression of MHC class I molecules on beta cells
}

\author{
X.-B. Li ${ }^{1}$, F.W. Scott ${ }^{2}$, Y.H. Park ${ }^{1}$, J.-W. Yoon ${ }^{1}$ \\ ${ }^{1}$ Laboratory of Viral and Immunopathogenesis of Diabetes, Julia McFarlane Diabetes Research Centre, The University of Calgary \\ Health Science Centre, Calgary, Alberta, Canada \\ ${ }^{2}$ Nutrition Research Division, Food Directorate, Health Canada, Banting Research Centre, Tunney's Pasture, Ottawa, Ontario, \\ Canada
}

\begin{abstract}
Summary Diabetes-prone BioBreeding (DPBB) rats were fed a diabetogenic, mainly plant-based rodent diet, Purina Chow 5001, or a diabetes-retardant, hydrolysed casein-based diet. The expression of MHC class I antigens on pancreatic beta cells occurred at around 25 days of age in Purina Chow-fed rats, and progressively increased with the length of time of feeding with the Purina diet. Most of the Purina Chow-fed DPBB rats revealed hyperexpression of MHC class I antigens on their pancreatic beta cells by 50 days of age. Approximately $92 \%$ of the hyperexpressed Purina Chow-fed DPBB rats developed severe insulitis and diabetes. In contrast, the majority of hydrolysed casein-fed DPBB rats did not show MHC class I antigen hyperexpression and these rats failed to develop insulitis or diabetes. Purina Chow-fed Wistar-Furth rats and diabetes-resistant BioBreeding (DRBB) rats showed only very weak background staining for MHC class I antigens on their beta cells.
\end{abstract}

When Purina Chow-fed DPBB rats were treated with silica to inhibit macrophage infiltration into the pancreatic islets, the hyperexpression of MHC class I antigens was seen even more clearly, as beta cells remained intact. MHC class II antigens were not detected on pancreatic beta cells from DPBB, DRBB or Wistar-Furth rats, regardless of their diet. On the basis of these observations, we concluded that hyperexpression of $\mathrm{MHC}$ class I antigens on pancreatic beta cells was mainly restricted to Purina Chow-fed DPBB rats and that suppression of non-macrophage-dependent MHC class I antigen hyperexpression on pancreatic beta cells by a hydrolysed caseinbased diet resulted in the prevention of insulitis and diabetes. [Diabetologia (1995) 38: 1138-1147]

Key words Pathogenesis, major histocompatibility complex, BioBreeding rat, autoimmunity.
The diabetic syndrome in the diabetes-prone BioBreeding (DPBB) rat resembles human type 1 insulin-dependent diabetes mellitus (IDDM) and is the result of a progressive autoimmune process directed

Received: 3 February 1995 and in revised form: 5 April 1995

Corresponding author: Dr. J.-W. Yoon, Julia McFarlane Diabetes Research Centre, University of Calgary Health Science Centre, 3330 Hospital Drive N. W., Calgary, Alberta, Canada T2N 4N1

Abbreviations: DPBB rat, diabetes-prone BioBreeding rat; DRBB rat, diabetes-resistant BioBreeding rat; NOD mouse, non-obese diabetic mouse; $\mathrm{HC}$, hydrolysed casein-based, semi-purified diet; PC, Purina Chow 5001 non-purified, cereal-based diet; WF rat, Wistar-Furth rat; $\mathrm{MHC}$, major histocompatibility complex; IDDM, insulin-dependent diabetes mellitus; PBS, phosphate buffered saline. against pancreatic beta cells [1-3]. While genetic susceptibility is a prerequisite for the development of diabetes, environmental factors also play an important role. Dietary factors have been shown to be major determinants of diabetes development in the DPBB rat and the non-obese diabetic (NOD) mouse [4-9].

Feeding DPBB rats with unrefined, natural ingredient feeding mixtures, such as Purina Chow 5001 (PC) or NIH-07, produces a high incidence of diabetes with approximately $70 \%$ of the animals becoming diabetic. In contrast, feeding the same animals with a modified American Institute of Nutrition formulation, AIN-76A, $[10,11]$ containing simpler refined ingredients, such as casein or hydrolysed casein (HC), corn oil, starch and micronutrients, results in less than $15 \%$ of the animals becoming diabetic. 
These results indicate that diet can dramatically alter the development of diabetes in the DPBB rat $[6,7$, $9,12]$. The diabetes frequency associated with each of the main ingredients of the diabetogenic NIH-07 diet has been determined [12]. When test constituents are fed as the sole source of protein in amino acid-sufficient diets, wheat and soybean meal are major sources of diabetogens $[4,5,8,13]$. However, the mechanism by which certain foods can modify the development of diabetes in DPBB rats is not known.

MHC class II polymorphism, particularly with respect to HLA-DQ alpha/beta heterodimers, is an important genetic marker of diabetes susceptibility. Experimental evidence that overexpression of $\mathrm{MHC}$ class I antigens on target beta cells may be involved in the pathogenesis of diabetes [14] is also increasing. Previous reports suggested that MHC class I and class II molecules are abnormally expressed on the pancreatic beta cells of the DPBB rat $[1,3,15,16]$. In addition, increased expression of MHC class I antigens on pancreatic beta cells may contribute to allograft rejection $[17,18]$. The timing of MHC antigen expression or overexpression, and whether it precedes or is the result of macrophage and lymphocyte infiltration into the islets remains controversial. The cause of abnormal expression of MHC molecules on pancreatic beta cells in susceptible individuals is not known $[14,19]$.

This investigation was conducted to see whether two diets, one markedly diabetes-retardant (HC), and the other highly diabetogenic (PC), could influence the expression of MHC class I or II antigens on pancreatic beta cells, and whether this expression was associated with the development of insulitis and diabetes in DPBB rats. We now report that the hyperexpression of MHC class I antigens seen in PC-fed DPBB rats is highly associated with the development of insulitis and diabetes, while the suppression of MHC class I antigens on pancreatic beta cells, induced by feeding the same animals with an $\mathrm{HC}$ diet, results in the prevention of insulitis and diabetes. In contrast, MHC class II antigens were not detected on the pancreatic beta cells from either PC-fed or HC-fed DPBB rats.

\section{Materials and methods}

Animals and diets. The DPBB and diabetes-resistant BioBreeding (DRBB) rats used in these experiments were produced from breeding stock provided by the Animal Resources Division of Health Canada, Ottawa, Ontario, Canada, where the stock animals were maintained under specific pathogenfree conditions. At The University of Calgary, the animals were housed under filtered air, on one of the autoclaved diets described below. Animals were maintained according to the guidelines of the Canadian Council for Animal Care.

The diabetes-retardant, hydrolysed casein ( $\mathrm{HC}$ ) diet used was a modification of the American Institute of Nutrition recommended diet for rats and mice, AIN-76A $[10,11]$, contain- ing: $20 \%$ casein hydrolysate (Pancase S, Champlain Industries, Mississauga, Ontario, Canada), $64.95 \%$ cornstarch, $5 \%$ corn oil, $5 \%$ purified wood cellulose (Solka-Floc, 200 FC, Teklad, Madison, Wis., USA), 3.5\% AIN-76A mineral mix, $1 \%$ AIN-76A vitamin mix, $0.3 \%$ DL-methionine, $0.2 \%$ choline bitartrate, and $0.05 \%$ L-tryptophan. Purina Chow 5001 (PC) (PMI Feeds, St.Louis, Missouri, USA) is a closed-formula, mainly plant-based diet, which is consistently associated with a high frequency of diabetes in DPBB rats. Its ingredients include: ground extruded corn, soybean meal, ground oats, dried beet pulp, wheat germ meal, fish meal, brewers' dried yeast, alfalfa meal, cane molasses, dried whey, meat meal, wheat middlings, animal fat preserved with botylated hydroxy anisol (BHA), dicalcium phosphate, calcium carbonate, salt, calcium iodate, vitamin $\mathrm{B}_{12}$ supplement, DL-methionine, calcium pantothenate, choline chloride, folic acid, riboflavin supplement, thiamine, niacin supplement, pyridoxine hydrochloride, ferrous sulphate, vitamin A supplement, D-activated animal sterol, vitamin $\mathrm{E}$ supplement, ferrous carbonate, manganous oxide, cobalt carbonate, copper sulphate, zinc sulphate, and zinc oxide. Protein account for $23 \%$ of the total composition, with the following amino acids forming the respective percentages of the total composition: arginine, 1.38; cystine, 0.32 ; glycine, 1.20 ; histidine, 0.55 ; isoleucine, 1.18 ; leucine, 1.70 ; lysine, 1.42 ; methionine, 0.43 ; phenylalanine, 1.03 ; tyrosine, 0.68; threonine, 0.91; tryptophan, 0.29; and valine, 1.21. Fat accounts for $4.5 \%$ of the total composition of PC.

This study consisted of four separate experiments. For the first experiment, which examined the effect of diet on the development of insulitis and diabetes, four groups of animals were used. The groups consisted of 21 DPBB rats fed the PC diet, 22 DPBB rats fed the $\mathrm{HC}$ diet, $9 \mathrm{DRBB}$ rats fed the $\mathrm{PC}$ diet, and $7 \mathrm{DRBB}$ rats fed the $\mathrm{HC}$ diet. The animals were fed the specified diets from time of weaning until the termination of the experiment at 120 days of age, at which time pancreatic histology was examined as described below. In addition, the dams were fed the same diets as their offspring while pregnant and nursing. Beginning at 50 days of age, urinary glucose and ketone levels were determined twice weekly with Diastix and Ketostix reagent strips (Miles Laboratory Ltd, Etobicoke, Ontario, Canada). Individual rats were classified as diabetic on the basis of positive $(>2+)$ glycosuria and the diagnosis was confirmed on the basis of hyperglycaemia (blood glucose $>16.7 \mathrm{mmol} / \mathrm{l}$ ) on 2 consecutive days. Wistar-Furth (WF) rats were used as controls and were purchased from Harlan-Sprague-Dawley, Indianapolis, Ind., USA. Twelve WF rats were PC-fed and 11 WF rats were $\mathrm{HC}$-fed. The dams of the control rats were fed the same diets as their offspring while pregnant and nursing.

For the second experiment, which examined the effect of diet on the expression of MHC class I and class II antigens on pancreatic beta cells, as well as whether or not there was an association between MHC antigen expression and the development of insulitis and diabetes, 21 DPBB rats, 10 of which were silica-treated from 30 to 90 days of age to prevent insulitis [20], 7 DRBB rats, and 9 WF rats were all fed the PC diet. Nineteen DPBB rats, of which 9 were silica-treated [20], and 6 DRBB rats were all fed the $\mathrm{HC}$ diet. The animals were fed the specified diets from weaning until the termination of the experiment at 100 days of age. As described above, the dams of these rats were fed the same diet as their offspring while pregnant and nursing. Diabetes was diagnosed as described above. MHC class I and II antigen expression on the beta cells at 100 days of age in these animals, as well as development of insulitis were determined.

For the third experiment, which examined the effect of diet on the expression of MHC class I antigens on cells other than beta cells as well as the effect of diet on the expression of 
MHC class I antigens on beta cells at various ages, 30 DPBB rats were fed the PC diet and 24 DPBB rats were fed the HC diet. These animals were examined at 5,25, and 50 days of age. As described above, the dams of these rats were fed the same diet as their offspring while pregnant and nursing. MHC class I antigen expression on other tissues, such as stratified squamous epithelium of the oesophagus and peripheral nerve bundles of the tongue, was determined as described below.

For the fourth experiment, which examined expression of MHC antigens and the development of insulitis and diabetes at various ages, two groups comprising a total of 94 DPBB rats were fed the PC-diet. The first group of 44 PC-fed rats was used to examine MHC class I and II antigen expression at $5,25,50,75$ and 100 days of age. Of these 44 animals, the 31 animals examined at 50,75 , and 100 days of age were silica-treated to prevent insulitis [20], while the 13 animals examined at 5 and 25 days of age were not silica-treated. The second group of 50 PC-fed DPBB rats was examined for the development of insulitis and diabetes at the same ages. As described above, the dams of these rats were fed the same diet as their offspring while pregnant and nursing. Rats were classified as diabetic by the test result criteria described above. MHC class I and II antigen expression on the beta cells and the development of insulitis were determined.

At the end of the experiments, the animals were killed by placing them in a $\mathrm{CO}_{2}$ chamber.

\section{Histological examination of pancreatic islets}

Light microscopy. Pancreata were fixed with $10 \%$ buffered formalin and embedded in paraffin. Pancreatic sections $(5 \mu \mathrm{m})$ were stained with haematoxylin and eosin [20]. The infiltration of mononuclear cells into the pancreatic islets was arbitrarily classified as early, intermediate, late, or end-stage insulitis, according to the following morphological criteria [21]. The early stage of insulitis consisted of an accumulation of mononuclear cells at the periphery of, or just within, the islets. In intermediate-stage insulitis, mononuclear cells infiltrated the centre of the islet, but left the islet architecture relatively well-preserved. In late-stage insulitis, the islet architecture was distorted and infiltration by mononuclear cells was markedly increased. Final, end-stage insulitis was characterized by small, retracted islets with or without small numbers of residual infiltrating cells.

Identification of beta cells by anti-insulin antibody staining. Cryostat sections $(5 \mu \mathrm{m})$ were cut from frozen pancreata, mounted on slides, and then air-dried for $30 \mathrm{~min}$, followed by acetone fixation for $10 \mathrm{~min}$. The slides were dried again for $15 \mathrm{~min}$, then stored at $-70^{\circ} \mathrm{C}$ before use. The pancreatic sections were incubated with $0.1 \mathrm{ml}(10-20 \mu \mathrm{g} / \mathrm{ml}$ in phosphate buffered saline (PBS) of the anti-insulin monoclonal antibody obtained from hybridoma CC9C10 (ATCC, Rockville, Md, USA) for $30 \mathrm{~min}$ at room temperature. After a 15 -min wash in PBS, the slides were incubated with fluorescein-labelled anti-mouse immunoglobulin (Kirkegaard \& Perry Laboratory, Gettysburg, Md., USA) for $30 \mathrm{~min}$. The sections were then washed again for $15 \mathrm{~min}$ in PBS, three times, followed by examination under an Olympus microscope (Olympus Optical Co. Ltd., Tokyo, Japan).

Expression of MHC antigens on pancreatic beta cells and other tissues. For examination of MHC class I and II antigen expression in three of the experiments described above (the second,
Table 1. Effect of diet on the development of diabetes

\begin{tabular}{llrll}
\hline Diet & $\begin{array}{l}\text { Rat } \\
\text { strain }\end{array}$ & $\begin{array}{l}\text { Ani- } \\
\text { mals } n\end{array}$ & $\begin{array}{l}\text { Insulitis } \\
(\%)\end{array}$ & $\begin{array}{l}\text { Diabetes } \\
(\%)^{\mathrm{a}}\end{array}$ \\
\hline Purina & DPBB & 21 & $21 / 21(100 \%)^{\mathrm{a}}$ & $\begin{array}{l}16 / 21(76 \%)^{\mathrm{a}, \mathrm{b}} \\
\text { chow }\end{array}$ \\
& DRBB & 9 & $0 / 9(0 \%)$ & $0 / 9(0 \%)$ \\
& WF & 12 & $0 / 12(0 \%)$ & $0 / 12(0 \%)$ \\
Hydrolys- & DPBB & 22 & $6 / 22(27 \%)$ & $4 / 22(18 \%)$ \\
ed casein & DRBB & 7 & $0 / 7(0 \%)$ & $0 / 7(0 \%)$ \\
& WF & 11 & $0 / 11(0 \%)$ & $0 / 11(0 \%)$ \\
\hline
\end{tabular}

Individual rats were classified as diabetic on the basis of positive (over 2+) glycosuria, and the diagnosis was confirmed on the basis of blood glucose level $>16.7 \mathrm{mmol} / \mathrm{l}$ on consecutive days. ${ }^{a}$ Cumulative diabetes incidence by 120 days of age. ${ }^{\mathrm{b}}$ DPBB rats, PC vs HC diet, Fisher's exact test $p<0.0002$

third and fourth experiments), we stained tissue sections with anti-MHC class I or II antibodies.

Briefly, serial cryostat sections ( $5 \mu \mathrm{m})$ were cut from frozen pancreata or other tissues, mounted on gelatin-coated slides, then fixed with acetone for $10 \mathrm{~min}$ and stored at $-70^{\circ} \mathrm{C}$ before use. Slides were washed in PBS plus $1 \%$ normal goat serum and immersed in $0.03 \% \mathrm{H}_{2} \mathrm{O}_{2} / 1 \%$ bovine serum albumin for $10 \mathrm{~min}$. The slides were then incubated with $0.5 \%$ avidin (Vector Laboratories Inc., Burlington, Ontario, Canada) followed by $0.1 \%$ biotin (Vector) for $30 \mathrm{~min}$ to block endogenous biotin reactive sites. Sections were incubated with monoclonal antibodies, OX18 for MHC class I antigens and OX6 for MHC class II antigens (Cedarlane Laboratories, Hornby, Ontario, Canada) for $60 \mathrm{~min}$, followed by biotinylated horse anti-mouse IgG (Vector) and avidin horseradish peroxidase (Vector) at $5 \mu \mathrm{g} / \mathrm{ml}$ for $60 \mathrm{~min}$. The colour reaction was manifested by incubating the slides in diaminobenzoic acid solution (Vector). The colour reaction was enhanced by briefly immersing the slides in a $2 \%$ solution of $\mathrm{CuSO}_{4}$, followed by counterstaining with haematoxylin. Spleen sections were used as a positive control. Pancreatic and spleen sections, in which the primary monoclonal antibodies had been omitted, were used as negative controls.

\section{Statistical analysis}

Fisher's exact test was used to compare the frequencies of diabetes and insulitis. Subjective histological grades are presented as representative grades for each condition.

\section{Results}

Effect of diet on body weight and on the development of insulitis and diabetes. To see whether there was any difference in the mean body weight of PC-fed and HC-fed DPBB and DRBB rats, we measured body weights weekly. There was no significant difference in the mean body weight among the groups of animals.

When we examined pancreatic islets from the 21 PC-fed DPBB rats, all had some degree of insulitis present (Table 1). In addition, 16 of 21 of these PCfed DPBB rats $(76 \%)$ became diabetic by 120 days 
Table 2. Association between expression of MHC antigens and development of insulitis and diabetes

\begin{tabular}{|c|c|c|c|c|c|}
\hline \multirow[t]{2}{*}{ Diet } & \multirow[t]{2}{*}{ Rat strain } & \multicolumn{2}{|c|}{ Expression of MHC antigens on beta cells ${ }^{\mathrm{a}}$} & \multirow[t]{2}{*}{ Insulitis } & \multirow[t]{2}{*}{ Diabetes $^{b}$} \\
\hline & & Class I & Class II & & \\
\hline \multirow[t]{3}{*}{ Purina chow } & $\mathrm{DPBB}^{\mathrm{c}}$ & $++(11 / 11)$ & ND & $11 / 11^{\mathrm{d}}$ & $8 / 11$ \\
\hline & DRBB & $+/-(7 / 7)$ & ND & $0 / 7$ & $0 / 7$ \\
\hline & WF & $+1-(9 / 9)$ & ND & $0 / 9$ & $0 / 9$ \\
\hline Hydrolysed casein & $\mathrm{DPBB}^{\mathrm{c}}$ & $+i-(9 / 10)^{\mathrm{f}}$ & ND & $1 / 10^{\mathrm{f}, \mathrm{g}}$ & $1 / 10^{\mathrm{f}}$ \\
\hline
\end{tabular}

a Pancreatic sections from various strains of rats aged 100 days were stained with monoclonal antibody, OX18 for MHC class I antigens and OX6 for MHC class II antigens. "+/-" = background staining, "+", weak staining, "++", intermediate staining, and " +++ " strong staining. A total of 72 to 96 islets were examined. All the PC-fed DRBB and WF, and HC-fed DPBB and DRBB rats showed only background staining $(+/-)$. Over $80 \%$ of islets examined from PC-fed DPBB rats without silica treatment showed intermediate staining $(++)$ and over $90 \%$ of islets examined from silica-treated PC-fed DPBB rats showed strong staining $(+++)$.

${ }^{\mathrm{b}}$ Cumulative diabetes incidence by 100 days of age. Individual rats were classified as diabetic on the basis of positive (over $2+$ ) glycosuria, and the diagnosis was confirmed on the basis of a blood glucose level $>16.7 \mathrm{mmol} / 1$ on consecutive days
${ }^{\mathrm{c}}$ Expression of $\mathrm{MHC}$ antigens on residual beta cells from $\mathrm{PC}-$ fed DPBB rats not treated with silica

DDegree of insulitis ranged from intermediate to end stage. See Materials and methods - Histological examination of pancreatic islets

e PC-fed DPBB and HC-fed DPBB rats were treated twice weekly with silica from 30 until 90 days of age to inhibit betacell destruction

${ }^{\mathrm{f}}$ of $10 \mathrm{HC}$-fed DPBB rats, 9 showed only weak staining for MHC class I antigens, while the remaining rat showed ++ staining of the islets. This rat also showed insulitis and diabetes g Degree of insulitis ranged from early to late stage. See Materials and methods - Histological examination of pancreatic islets

ND, Not detected of age (Table 1) and the islets from these rats showed severe insulitis. When we examined pancreatic islets from the 5 of 21 non-diabetic PC-fed DPBB rats, we observed that over $70 \%$ of the islets from these animals showed intermediate-stage insulitis and the remaining $30 \%$ of islets showed early-stage insulitis. None of the PC-fed DRBB or WF rats developed insulitis or diabetes (Table 1 ).

There was however, a significant difference in the incidence of insulitis and diabetes between the PCfed and HC-fed DPBB rats. Only 6 of $22(27 \%)$ HCfed DPBB rats developed insulitis compared to $100 \%$ of the PC-fed DPBB rats, and only 4 of 22 $(18 \%)$ of HC-fed DPBB rats developed diabetes by 120 days of age (Table 1 ). Pancreatic islets from the four diabetic HC-fed DPBB rats showed severe insulitis while pancreatic islets from the two non-diabetic HC-fed DPBB rats with insulitis showed early or intermediate-stage insulitis. None of the HC-fed DRBB or WF rats developed insulitis or diabetes (Table 1).

These results indicate that the $\mathrm{HC}$ diet clearly inhibits the development of insulitis and diabetes in DPBB rats and that the effect of diet on the development of insulitis and diabetes was strictly restricted to genetically predisposed DPBB rats.

Effect of diet on expression of MHC class I and class II antigens on pancreatic beta cells and association of $M H C$ antigen expression and the development of insulitis and diabetes. To see whether there was any difference in the expression of MHC class I and class II an- tigens on pancreatic beta cells from several different groups of rats, including 11 PC-fed DPBB, 7 PC-fed DRBB, 9 PC-fed WF, $10 \mathrm{HC}$-fed DPBB, and $6 \mathrm{HC}$ fed DRBB rats, islets were examined from rats aged 100 days. Pancreatic islets from the 11 PC-fed DPBB rats clearly showed hyperexpression of MHC class I antigens (Table 2). All 11 of these PC-fed DPBB rats developed insulitis by 100 days of age and 8 of 11 became diabetic by the same age (Table 2 ).

In contrast, with the exception of the one HC-fed DPBB rat that became diabetic, islets from HC-fed DPBB rats showed only very weak background staining for MHC class I antigens (Table 2). There was essentially no difference in expression of MHC class I antigens among islets from PC-fed WF, PC-fed DRBB, HC-fed DPBB and HC-fed DRBB rats, indicating that hyperexpression of MHC class I antigens was mainly restricted to islets from PC-fed DPBB rats (Table 2). None of the PC-fed DRBB or WF rats developed insulitis or diabetes. Similarly all of the HC-fed DRBB rats and 9 of $10 \mathrm{HC}$-fed DPBB rats were free of insulitis and diabetes. None of the pancreatic islets from any of the groups of animals expressed MHC class II antigens, regardless of diet (Table 2). In contrast, spleen sections from PC-fed DPBB rats, which contain activated macrophages, showed positive staining for MHC class II antigens.

Expression of $M H C$ class $I$ and class $I I$ antigens in silica-treated $D P B B$ rats. To see whether there were any differences in the expression of MHC class I and II antigens between PC-fed, and HC-fed DPBB rats, 


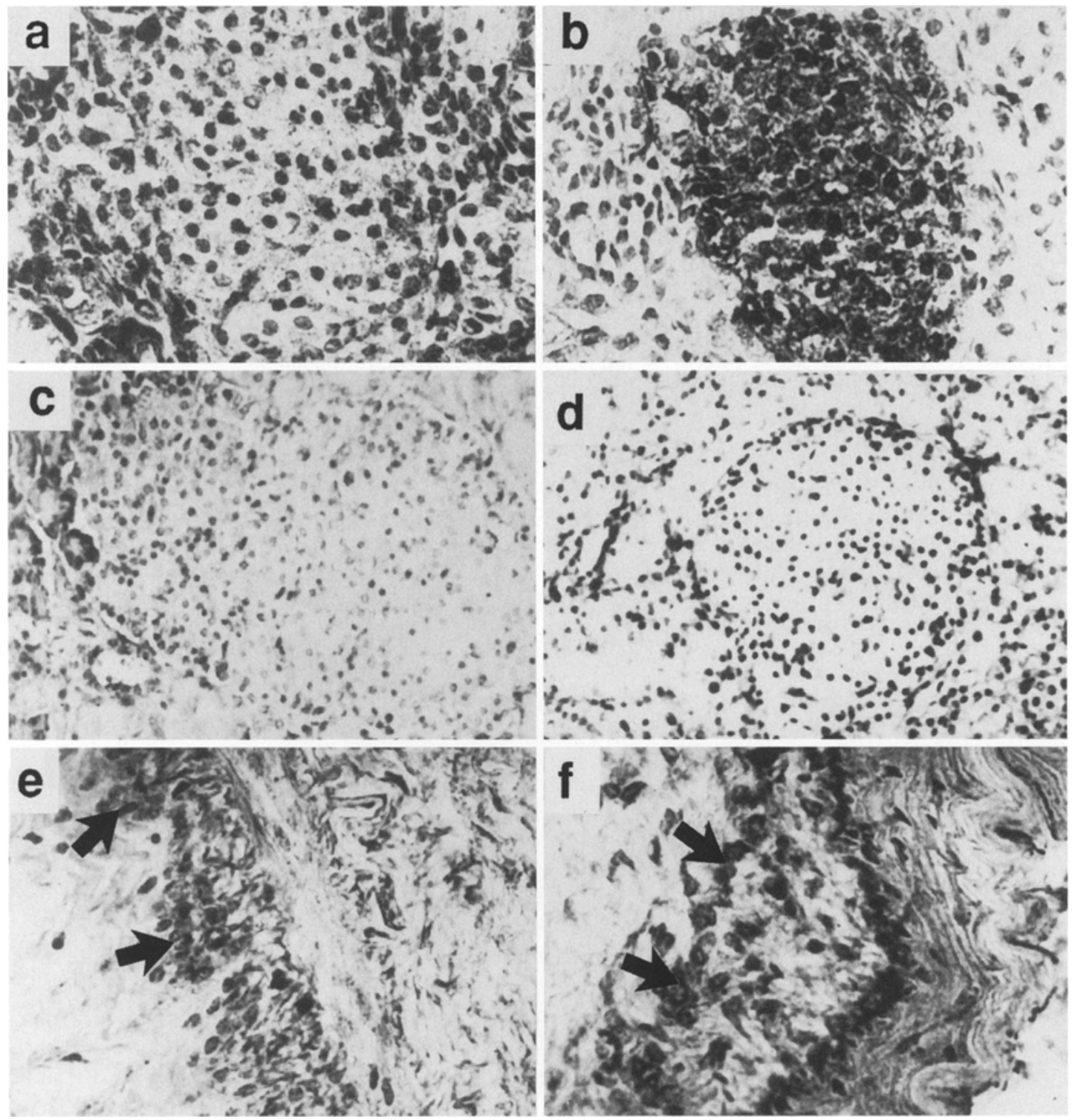

Fig. 1a-f. Expression of MHC class I and II antigens on pancreatic islet cells and stratified squamous epithelium of oesophagus from HC-fed and PC-fed DPBB rats. Sections of pancreata from silica-treated HC-fed 100-day-old DPBB rats (a) or silica-treated PC-fed 100-day-old DPBB rats (b) stained with monoclonal antibody, OX18, against MHC class I antigens. Islets from (a) show negative staining $(\times 400)$, while islets from (b) show strong, positive staining $(x 400)$. Pancreatic sections from silica-treated HC-fed 100-day-old DPBB rats $($ c) $(\times 200)$ and silica-treated $P C$-fed 100-day-old rats (d) $(\times 200)$ stained with monoclonal antibody, OX6, against MHC class II antigens. Islets from both (c) and (d) show negative staining. Sections of oesophagus from $\mathrm{HC}$-fed 50-day-old DPBB rats $(\mathbf{e})(\times 400)$ and PC-fed 50-day-old DPBB rats $(\mathbf{f})$ $(\times 400)$ stained with monoclonal antibody, OX18, for MHC class I antigens. Stratified squamous epithelium of the oesophagus from both (e) and (f) show strong positive staining for MHC class I antigens (arrows) these animals were treated with silica twice weekly between 30 and 90 days of age to inhibit beta-cell destruction and permit examination of the islets. MHC class I hyperexpression was even more clearly seen in the silica-treated PC-fed DPBB rats (Table 2; Fig. 1b), since intact beta cells were present in their islets, while islets from silica-treated HC-fed DPBB rats showed only very weak background staining (Table 2; Fig. 1a). In contrast, MHC class II antigens were not expressed on the pancreatic beta cells from either HC-fed or PC-fed silica-treated DPBB rats (Table 2; Fig. 1c, d).

\section{Effect of diet on expression of $M H C$ class I antigens} on cells other than pancreatic beta cells. To see whether diet also influenced the expression of MHC class I antigens on cells other than pancreatic beta cells, sections of oesophagus and tongue from PCfed and HC-fed DPBB rats, aged 5, 25 and 50 days, were examined after staining with monoclonal anti- 
Table 3. Expression of MHC class I antigens on various tissues at different ages in PC-fed and HC-fed DPBB rats

\begin{tabular}{lcllll}
\hline Age (days) & Rats $(n)$ & Diet & \multicolumn{4}{l}{ Expression of MHC Class I antigens } \\
\cline { 3 - 6 } & & & Islets & Epithelium of the oesophagus & Peripheral nerve bundles of the tongue \\
\hline 5 & 9 & PC & $+/^{\mathrm{b}}(9 / 9)$ & $++^{\mathrm{c}}(8 / 9)$ & $++^{\mathrm{c}}(8 / 9)$ \\
& 8 & HC & $+/^{\mathrm{b}}(8 / 8)$ & $++^{\mathrm{c}}(7 / 8)$ & $++^{\mathrm{c}}(7 / 8)$ \\
25 & 10 & PC & $+^{\mathrm{d}}(6 / 10)$ & $++^{\mathrm{c}}(9 / 10)$ & $++^{\mathrm{c}}(9 / 10)$ \\
& 9 & HC & $+-^{\mathrm{b}}(8 / 9)$ & $++^{\mathrm{c}}(8 / 9)$ & $++^{\mathrm{c}}(8 / 9)$ \\
50 & 11 & PC & $++^{\mathrm{c}}(10 / 11)$ & $++^{\mathrm{c}}(11 / 11)$ & $++^{\mathrm{c}}(11 / 11)$ \\
& 7 & HC & $+/-^{\mathrm{b}}(5 / 7)$ & $++^{\mathrm{c}}(7 / 7)$ & $++^{\mathrm{c}}(7 / 7)$
\end{tabular}

a Tissue sections from pancreas, oesophagus and tongue were stained with monoclonal antibody, OX18 for MHC class I antigens. "+/-", very weak background staining; "+", weak staining; " ++ ", intermediate staining. A total of 29 to 36 sections from each tissue were examined. Three to five sections per rat were examined; thus approximately 24 to 40 islets per rat ( $\sim 8$ islets per section) were examined. Numbers in parentheses are rats per group with this representative grade.
${ }^{\mathrm{b}}$ All examined tissues showed very weak background staining $(+/-)$

c Over $90 \%$ of the examined tissues showed intermediate staining $(++)$

${ }^{\mathrm{d}}$ Over $90 \%$ of the examined tissues showed weak staining $(+)$

Table 4. Expression of MHC antigens and development of insulitis and diabetes at different ages in PC-fed DPBB rats

\begin{tabular}{|c|c|c|c|c|c|c|c|c|c|c|c|}
\hline \multirow[b]{2}{*}{$\begin{array}{l}\text { Age } \\
\text { (days) }\end{array}$} & \multicolumn{3}{|c|}{ Expression of MHC antigens on beta cells } & \multirow[b]{2}{*}{$\begin{array}{l}\text { Rats } \\
(n)\end{array}$} & \multirow[b]{2}{*}{$\begin{array}{l}\text { Islets } \\
(n)\end{array}$} & \multicolumn{5}{|c|}{ Insulitis $^{\mathrm{a}}$} & \multirow[t]{2}{*}{ Diabetes (\%) } \\
\hline & $\begin{array}{l}\text { Rats }^{\mathbf{b}} \\
(n)\end{array}$ & Class I & Class II & & & $\begin{array}{l}\text { Nor- } \\
\text { mal }\end{array}$ & Early & $\begin{array}{l}\text { Inter- } \\
\text { mediate }\end{array}$ & Late & End & \\
\hline 25 & 7 & $+(4 / 7)$ & ND & 10 & 86 & 86 & 0 & 0 & 0 & 0 & 0 \\
\hline 50 & 10 & $++(8 / 10)$ & $\mathrm{ND}$ & 10 & 127 & 115 & 8 & 4 & 0 & 0 & 0 \\
\hline 75 & 10 & $+++(8 / 10)$ & $\mathrm{ND}$ & 10 & 142 & 56 & 59 & 21 & 5 & 1 & 10 \\
\hline
\end{tabular}

${ }^{a}$ See Materials and Methods for the definitions of early, intermediate, late and end-stage insulitis.

${ }^{\mathrm{b}}$ For the examination of MHC antigen expression on beta cells, PC-fed DPBB rats aged 5 and 25 days (not treated with silica) were killed. To inhibit beta-cell destruction in the older rats, those aged 50, 75, and 100 days were treated twice weekly with silica from 30 until 90 days of age. Num-

body OX18 for MHC class I antigens. MHC class I antigens were highly expressed on the stratified squamous epithelium of the oesophagus, as well as on the peripheral nerve bundles of the tongue, regardless of diet or age (Table 3, Fig.1e, f). The expression of MHC class I antigens on pancreatic beta cells occurred around 25 days of age in PC-fed DPBB rats and clearly increased by 50 days of age. In contrast, MHC class I antigens were definitely suppressed on pancreatic beta cells from HC-fed DPBB rats (Table 3 ).

\section{Expression of MHC class I antigens and development} of insulitis and diabetes at various ages. To see whether the association between the expression of MHC class I antigens and development of insulitis and diabetes we found in 100-day-old PC-fed DPBB rats exists at different ages, we examined two groups of PCfed DPBB rats, one for the expression of MHC class I antigens and the other for the incidence of insulitis and diabetes, at the ages of $5,25,50,75$, and 100 bers in parentheses are rats per group with this representative grade.

${ }^{\circ}$ In a parallel experiment to examine islet histology, ten PC-fed DPBB rats (not treated with silica) were killed at 5, 25, 50, 75 and 100 days of age. The diabetes frequency at each age is also shown

ND, Not detected

days of age. At 5 days of age, none of the PC-fed DPBB rats showed any MHC class I antigen expression or insulitis (Table 4). At 25 days of age, 4 out of 7 rats exhibited mild expression of MHC class I antigens, but no insulitis was observed in examined islets (Table 4). However, at 50 days of age, expression of MHC class I antigens was clearly evident in 8 out of 10 rats and about $10 \%$ of the islets examined showed early or intermediate stage insulitis (Table 4). At 75 days of age, hyperexpression of MHC class I antigens was observed in 8 out of 10 rats; $41 \%$ of examined islets showed early stage insulitis and $19 \%$ showed intermediate to late-stage insulitis (Table 4). At 100 days of age, hyperexpression of MHC class I antigens was observed in 10 of 11 PC-fed silica-treated DPBB rats, and $82 \%$ of islets from untreated age-matched PC-fed DPBB rats showed intermediate to late-stage insulitis (Table 4). When the islets from 100-day-old PC-fed silica-treated DPBB rats were reacted with anti-insulin antibody, they showed positive staining, indicating that the observed hyper- 

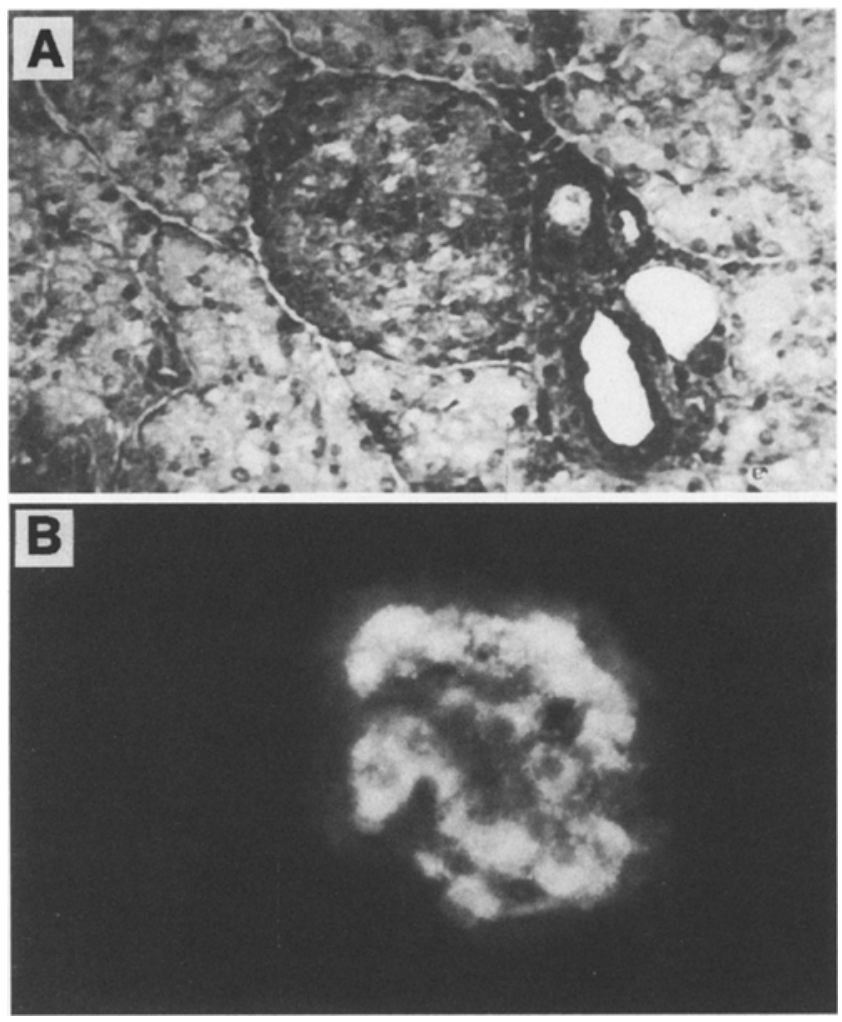

Fig. 2A, B. Anti-insulin antibody staining and MHC antibody staining. A section of pancreas from a 100-day-old PC-fed silica-treated DPBB rat stained with monoclonal antibody OX18 against MHC class I antigens ( $\mathbf{A}$ ) shows MHC class I antigen expression in the islets $(\times 200)$. Staining of a section from the same tissue block (but at some distance) with anti-insulin antibody (B) reveals that the cells expressing the MHC class I antigens contain insulin and are beta cells $(\times 200)$

expression of MHC class I antigens was on insulincontaining beta cells (Fig. $2 \mathrm{a}, \mathrm{b}$ ).

\section{Discussion}

Cumulative evidence shows that diet, particularly the source of dietary protein, affects the expression of the diabetic syndrome in $\mathrm{BB}$ rats $[4-7,9]$, and nonobese diabetic (NOD) mice $[8,22]$, and there is some circumstantial evidence suggesting that diet plays a role in the development of human autoimmune IDDM [23]. The exact role of diet in the pathogenesis of diabetes has not been precisely elucidated. Earlier studies on the effects of certain dietary manipulations on the immune systems of DPBB rats did not indicate major diet-related alterations in the distribution of macrophages $\left(\mathrm{OX} 41^{+}\right)$or pan $\mathrm{T}$ cells $\left(\mathrm{OX} 19^{+}\right)$, helper/inducer $\mathrm{T}$ cells $\left(\mathrm{W} 3 / 25^{+}\right)$, or cytotoxic/suppressor $\mathrm{T}$ lymphocytes $\left(\mathrm{OX}^{+}\right)$in the peripheral blood $[4,9,24]$.

Our investigation was initiated to determine if there is an association between the degree of MHC class I antigen expression on pancreatic beta cells and subsequent development of insulitis and diabetes in DPBB rats fed a diabetes-retardant HC diet or a diabetogenic PC diet. The PC diet induced hyperexpression of MHC class I antigens on pancreatic beta cells and this hyperexpression was highly associated with the subsequent development of insulitis. In contrast, suppression of MHC class I antigen expression by a diabetes-retardant $\mathrm{HC}$ diet resulted in marked inhibition of insulitis. Furthermore, there was a clear association between the degree of MHC class I antigen expression and the degree of insulitis observed. Previous studies, using low-incidence hybrid DPBB $\times$ Buffalo (BUF) rats, showed that staining of pancreatic islets by anti-MHC class I antibodies was less intense in islets from 65-day-old animals fed diabetes-retardant casein-based diets (with safflower or menhaden fish oil as fat sources) compared with islets from animals fed Purina Chow 5012 [9]. In addition, MHC class I mRNA expression was enhanced around 40-50 days of age in other hybrid $\mathrm{DPBB} \times \mathrm{BUF}$ rats [25]. These results support our findings, even though a hybrid strain of rat with a low incidence of diabetes was used.

To see whether the increased expression of MHC class I antigens observed in the earlier studies was truly the result of an inflammatory infiltrate, as previously thought [25], we treated PC-fed DPBB rats with silica to inhibit infiltration of inflammatory cells into the pancreatic islets. We then examined islets from silica-treated PC-fed DPBB rats of various ages to see whether there was any difference in expression of MHC class I antigens on the beta cells. We confirmed that treatment of DPBB rats with silica prevents insulitis $[20,26]$, and the hyperexpression of MHC class I antigens we observed in these silica-treated PC-fed animals was even more evident because of the presence of intact beta cells. These results show that hyperexpression of MHC class I antigens was not eliminated by silica treatment, and are consistent with a situation in which abnormal MHC class I antigen expression precedes the appearance of inflammatory infiltrates into the islets of DPBB rats.

We observed MHC class I antigen expression as early as 25 days of age in some of the high incidence DPBB rats, as compared to 40-50 days of age seen in the hybrid DPBB $\times$ BUF rat. The difference in time of expression observed was most likely a result of differences in genetic susceptibility to diabetes between the two strains of rats, in animal housing conditions, or of differences in the composition of the diets used in the two studies. While pups are generally weaned around 23 days of age, they do begin to nibble on the solid feed provided to the dam as early as 14 days of age. Exposure to the diabetogenic PC diet can therefore begin in advance of weaning, at around 14 days of age. It may therefore be suggested that expression of MHC class I antigens on beta cells 
in the DPBB rat can occur earlier in life than previously reported.

In addition, we looked at tissue specificity in the expression of MHC class I antigens in DPBB rats of different ages. We found that in tissues where MHC class I antigens are normally highly expressed, such as the stratified squamous epithelium of the oesophagus and peripheral nerve bundles of the tongue, MHC class I antigen expression was intermediate at all ages of animals examined, regardless of diet. This indicated that the $\mathrm{HC}$ diet did not affect $\mathrm{MHC}$ class I antigen expression on tissues other than pancreatic beta cells. We also looked at genetic differences in expression of MHC class I antigens, and found that DRBB and WF rats did not show hyperexpression of MHC class I antigens on their pancreatic beta cells when fed either diet.

Some HC-fed DPBB rats (10-18\%) developed insulitis and diabetes, and showed intermediate $(++)$ staining for MHC class I antigens. We do not know the reason for this; however, these rats may represent non-diet-inducible diabetes in the BB rat. Nonetheless, feeding with an $\mathrm{HC}$ diet routinely protected up to $90 \%$ of DPBB rats from the development of diabetes during the course of the experiment.

In contrast to MHC class I antigens, MHC class II antigens were not found on pancreatic beta cells from any strain of rat examined, regardless of diet. It was previously suggested that aberrant expression of MHC class II antigens on pancreatic beta cells might be important in the early period of beta-cell destruction [27, 28]; however, Hart et al. [29] showed that pancreatic beta cells do not normally express MHC class II molecules. Furthermore, several other studies using DPBB rats failed to detect MHC class II antigen expression on pancreatic beta cells $[16,25,30$, 31]. Infiltrating macrophages, which sometimes can stain positive for insulin, having phagocytosed damaged beta cells, were the only cells in the pancreatic islets on which MHC class II antigens were found to be expressed $[31,32]$. These studies support our present findings that MHC class II antigens are not expressed on pancreatic beta cells, regardless of diet, and that there is hyperexpression of only MHC class I antigens induced by a PC diet.

The mechanism by which a PC diet enhances the expression of MHC class I antigens on beta cells is not known. MHC class I antigens are glycoproteins and their determinants are peptides. It is possible that diet may either directly or indirectly affect the expression of these antigens on the target beta cell. The PC diet may contain a specific nutritional component, not present in the $\mathrm{HC}$ diet, and this component may upregulate synthesis of MHC class I antigens in association with insulin biosynthesis, resulting in beta cell-specific hyperexpression of MHC class I antigens. Alternatively, diet-induced alteration of the synthesis and release of cytokines, such as interferon alpha or gamma, tumour necrosis factor, or others, which are known to have the ability to modulate MHC class I antigen expression, may affect the expression of MHC class I antigens. Further studies will be required to determine the effects of specific dietary modifications on MHC class I antigen expression on beta cells.

It has been previously reported that induction of MHC class I antigens is correlated with impairment of beta-cell function $[16,25,30,31,33-37]$. When anti-MHC class $I\left(K^{d}\right)$ monoclonal antibodies were administered to cyclophosphamide-treated and untreated NOD mice, the incidence of diabetes was markedly reduced, suggesting that MHC class I antigens play an important, but as yet undefined role in the destruction of pancreatic beta cells in NOD mice [37]. This group further suggested that MHC class I expression was associated with $\mathrm{CD} 8^{+}$cytotoxic $\mathrm{T}$ lymphocytes in the destruction of pancreatic beta cells in NOD mice [34]. This finding was further supported by results from an investigation by Stock et al. [38] indicating that pre-treatment of islets with allospecific MHC class I monoclonal antibodies prevented generation of cytotoxic $\mathrm{T}$ lymphocytes in vitro in a mixed lymphocyte/islet co-culture system. Furthermore, if MHC class-I-deficient islets are used as donor tissue in an allogenic murine transplantation model, graft survival is dramatically prolonged [18]. Recent studies in MHC class I molecule-deficient NOD mice reported a virtual absence of insulitis in the presence of normal levels of NOD-derived MHC class II molecules, $\mathrm{A}^{\mathrm{g} 7}$, and a full $\mathrm{CD} 4^{+} \mathrm{T}$-cell compartment [39]. Others have also reported that MHC class I molecule expression on NOD beta cells increases with age and that the only MHC class IIpositive cells in the islets of NOD mice are CD $45^{+}$ cells of haematopoietic origin [40]. One interpretation of these data is that blockage of MHC class I molecules on islet cells prevented recognition by cytotoxic T lymphocytes.

The role of hyperexpressed MHC class I antigens in the development of insulitis in the DPBB rat is not known. Although our studies do not rule out the possibility of sporadic "single-cell" insulitis preceding MHC class I expression, on the basis of the evidence from studies on DPBB rats and NOD mice, we speculate that beta-cell-specific hyperexpression of MHC class I antigens may attract MHC class I-restricted $\mathrm{CD}^{+}$cytotoxic T lymphocytes, leading to the development of insulitis. Our hypothesis is supported by a recent report that MHC class I-restricted $\mathrm{CD} 8^{+} \mathrm{T}$ cells are required for the passive transfer of diabetes in the DPBB rat [41], even though the $\mathrm{DPBB}$ rat is T-cell lymphopenic and has very low levels of CD8 ${ }^{+} \mathrm{T}$ cells $[1-3]$. Furthermore, a cytotoxic response of $\mathrm{CD} 8^{+} \mathrm{T}$ lymphocytes from DPBB rats was observed in the presence of MHC class I hyperexpressed pancreatic islet cells [42]. Taken together, 
results from our study and those of others, suggest that early hyperexpression of MHC class I antigens on pancreatic beta cells, while not the earliest event, is an integral step in the development of insulitis and diabetes in the DPBB rat. Suppression of this MHC class I antigen hyperexpression by a hydrolysed-casein-based diet resulted in the prevention of insulitis and diabetes.

Acknowledgements. The authors gratefully acknowledge the technical assistance of H.E. Cloutier and J. Soligny from the Health Canada Laboratories in Ottawa, and the editorial help of $\mathrm{H}$. Kominek.

This work was supported by grant MA9584 from the Medical Research Council of Canada to J.-W. Y., who is also a Heritage Medical Scientist Awardee of the Alberta Foundation for Medical Research.

\section{References}

1. Crisá L, Mordes JP, Rossini AA (1992) Autoimmune diabetes mellitus in the BB rat. Diabetes Metab Rev 8: 9-37

2. Marliss EB (ed) (1983) The Juvenile Diabetes Foundation Workshop on the spontaneously diabetic BB rat: its potential for insight into human juvenile diabetes. Metab Clin Exp 32[Suppl 1]:1-166

3. Parfrey NA, Prud'homme GJ, Colle E, Fuks A, Seemayer TA, Guttmann RD. (1989) Immunologic and genetic studies of diabetes in the BB rat. Crit Rev Immunol 9: 45-65

4. Scott FW, Sarwar G, Cloutier HE (1988) Diabetogenicity of various protein sources in the diet of the BB rat. In: Camerini-Davalos RA, Cole HS (eds) Prediabetes. Plenum Press, New York, pp 277-285

5. Scott FW, Elliott RB, Kolb H (1989) Diet and autoimmunity: prospect of prevention of type 1 diabetes. Diabetes, Nutrition and Metabolism 2: 61-73

6. Scott FW, Marliss EB (1991) Conference summary: diet as an environmental factor in development of IDDM. Can J Physiol Pharmacol 69: 311-319

7. Elliott RB, Martin JM (1984) Dietary protein: a trigger of insulin-dependent diabetes in the $\mathrm{BB}$ rat? Diabetologia 26: 297-299

8. Hoorfar J, Buschard K, Dagnaes-Hansen F (1993) Prophylactic nutritional modification of the incidence of diabetes in autoimmune non-obese diabetic (NOD) mice. $\mathrm{Br} \mathrm{J}$ Nutr 69: 597-607

9. Issa-Chergui D, Guttmann RD, Seemayer TA, Kelley VE, Colle EC (1988) The effect of diet on the spontaneous insulin-dependent diabetic syndrome in the rat. Diabetes Res 9: 81-86

10. Bieri JG, Stoewsand GS, Briggs GM, Phillips RW, Woodward JC, Knapka JJ (1977) Report of the American Institute of Nutrition ad hoc committee on standards for nutritional studies. J Nutr 107: 1340-1348

11. Bieri JG (1980) Second report of the ad hoc committee on standards for nutritional studies. J Nutr 110: 1726

12. Scott FW (1994) Food, diabetes and immunology. In: Forse RA, Bell SJG, Blackburn L, Kabbash L (eds) Diet, nutrition and immunology. CRC Press, Boca Raton, Florida, pp $71-92$

13. Hoorfar J, Scott FW, Cloutier HE (1991) Dietary plant materials and development of diabetes in the BB rat. J Nutr 121: 908-916

14. Campbell RD, Milner CM (1993) MHC genes in autoimmunity. Curr Op Immunol 5: 887-893
15. Dean BM, Walker R, Bone AJ, Baird JD, Cooke A (1985) Pre-diabetes in the spontaneously diabetic BB/E rat: lymphocyte subpopulations in the pancreatic infiltrate and expression of rat MHC class $\Pi$ molecules in endocrine cells. Diabetologia 28: 464-466

16. Weringer E, Like AA (1988) Identification of T cell subsets and class I and class II antigen expression in islet grafts and pancreatic islets of diabetic BioBreeding/Worcester rats. Am J Pathol 132: 292-303

17. Markmann JF, Schachner MS, Bassiri H, Barker CF, Naji A (1990) The contribution of MHC modulation to islet allograft rejection. Horm Metab Res 25S:104-108

18. Osorio RW, Ascher NL, Jaenisch R et al. (1993) Major histocompatibility complex class I deficiency prolongs islet allograft survival. Diabetes 42: 1520-1527

19. Itoh N, Hanafusa T, Miyazaki A et al. (1993) Mononuclear cell infiltration and its relation to the expression of major histocompatibility complex antigens and adhesion molecules in pancreas biopsy specimens from newly diagnosed insulin-dependent diabetes mellitus patients. J Clin Invest 92: 2313-2322

20. Lee KU, Pak CY, Amano K, Yoon JW (1988) Prevention of lymphocytic thyroiditis and insulitis in diabetes-prone $\mathrm{BB}$ rats by the depletion of macrophages. Diabetologia 31: $400-402$

21. Lee KU, Kim MK, Amano K et al. (1988) Preferential infiltration of macrophages in the early stages of insulitis precedes the involvement of activated T-lymphocytes in the spontaneously diabetic BB rat. Diabetes 31: 10531058

22. Elliott RB, Reddy SN, Bibby NJ, Kida K (1988) Dietary prevention of diabetes in the non-obese diabetic mouse. Diabetologia 31: 62-64

23. Yoon JW (1995) Environmental factors in the pathogenesis of insulin dependent diabetes mellitus. In: Pickup J, Williams $\mathrm{G}$ (eds) Text book of diabetes. Blackwell, London, (in press)

24. Scott FW, Hoorfar J, Cloutier HE (1990) Lymphocytes and macrophages in $\mathrm{BB}$ rats fed diabetes-retardant or promoting diets. In: Shafrir E (ed) Frontiers in diabetes research: lessons from animal diabetes III. Smith-Gordon, London pp 192-194

25. Ono SJ, Issa-Chergui B, Colle E, Guttmann RD, Seemayer TA, Fuks A (1988) IDDM in BB rats: enhanced MHC class I heavy-chain gene expression in pancreatic islets. Diabetes 37: 1411-1418

26. Oschilewski U, Kiesel U, Kolb H (1985) Administration of silica prevents diabetes in BB rats. Diabetes 34: 197-199

27. Bottazzo GF, Dean BM, McNally JM, Mackay EH, Swift PGF, Gamble DR (1985) In situ characterization of autoimmune phenomena and expression of HLA molecules in the pancreas of diabetic insulitis. $N$ Engl J Med 313: 353-360

28. Foulis AK, Farquharson MA, Hardman R (1987) Aberrant expression of class II major histocompatibility complex molecules by B cells and hyperexpression of class I major histocompatibility complex molecules by insulin containing islets in type 1 (insulin-dependent) diabetes mellitus. Diabetologia 30: 333-343

29. Hart DNJ, Newton MR, Reece-Smith H, Fabre JW, Morris PJ (1983) Major histocompatibility complex antigens in the rat pancreas, isolated pancreatic islets, thyroid and adrenal. Transplantation 36: 431-435

30. Issa-Chergui B, Yale JF, Vigeant C, Seemayer TA (1988) Major histocompatibility complex gene product expression on pancreatic $\beta$ cells in acutely diabetic BB rats. Am J Pathol 30: 156-162 
31. Yoon JW, Ihm SH, Lee KU, Amano K, Pak CY (1988) The initial step in the development of organ specific autoimmune disease in BB rats. Diabetologia 31: 779-780 (Letter)

32. In't Veld PA, Pipeleers DG (1988) In-situ characterization of pancreatic islets in rats developing diabetes, appearance of nonendocrine cells with surface MHC class II antigens and cytoplasmic insulin reactivity. J Clin Invest 82: 11231128

33. Allison J, Campbell IL, Morahan G, Mandel TE, Harrison LC, Miller JFAP (1988) Diabetes in transgenic mice resulting from over-expression of class I histocompatibility molecules in pancreatic $\beta$-cells. Nature 333: 529-533

34. Hayakawa M, Yokono K, Nagata M et al. (1991) Morphological analysis of selective destruction of pancreatic beta cells by cytotoxic $\mathrm{T}$ lymphocytes in NOD mice. Diabetes 40: $1210-1217$

35. Leiter EH, Christianson GJ, Serreze DV, Ting AT, Worthen S (1989) MHC antigen induction by interferon- $\gamma$ on cultured mouse pancreatic $\beta$ cells and macrophages, genetic analysis of strain differences and discovery of an "occult" class I-like antigen in NOD/Lt mice. J Exp Med 170: 1243-1262

36. Serreze DV, Gaskins HR, Leiter EH (1993) Defects in the differentiation and function of antigen presenting cells in NOD/Lt mice. J Immunol 150: 2534-2543
37. Taki T, Nagata M, Ogawa W et al. (1991) Prevention of cyclophosphamide-induced and spontaneous diabetes in NON/Shi/Kbe mice by anti-class I $\mathrm{K}^{\mathrm{d}}$ monoclonal antibody. Diabetes 40: 1203-1209

38. Stock PG, Ascher NL, Chen S, Bumgardner GL, Field MJ, Sutherland ER (1989) Modulation of MHC class I antigen decrease pancreatic islet immunogenicity. J Surg Res 46: 317-321

39. Katz J, Benoist C, Mathis D (1993) Major histocompatibility complex class I molecules are required for the generation of insulitis in non-obese diabetic mice. Eur J Immunol 23: $3358-3360$

40. McInerney MF, Rath S, Janeway CA (1991) Exclusive expression of $\mathrm{MHC}$ class II proteins on $\mathrm{CD} 45^{+}$cells in pancreatic islets of NOD mice. Diabetes 40: 648-651.

41. Edouard P, Hiserodt JC, Plamondon C, Poussier P (1993) $\mathrm{CD}^{+} \mathrm{T}$-cells are required for adoptive transfer of the $\mathrm{BB}$ rat diabetic syndrome. Diabetes 42: 390-397

42. Bellgrau D, Lagarde AC (1990) Cytotoxic precursors with low level CD8 in the diabetes-prone Biobreeding rat: implications for generation of an autoimmune T-cell repertoire. PNAS 87: 313-317 